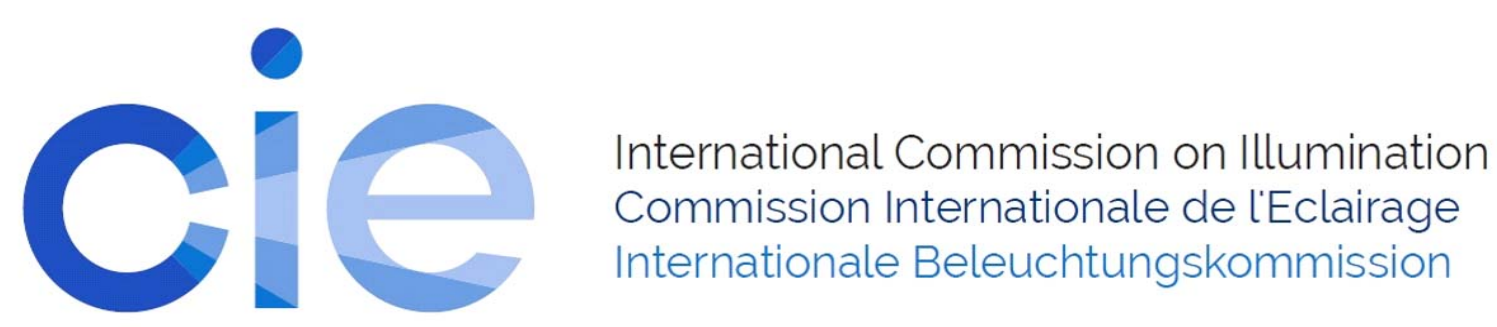

PP27

\title{
ANALYSIS AND DESIGN APPROACH FOR A NOCTURNAL IMAGE OF THE CULTURAL LANDSCAPE \\ Lodovica Valetti et al.
}

DOI 10.25039/x46.2019.PP27

from

CIE x046:2019

Proceedings

of the

29th CIE SESSION

Washington D.C., USA, June 14 - 22, 2019

(DOI 10.25039/x46.2019)

The paper has been presented at the 29th CIE Session, Washington D.C., USA, June 14-22, 2019. It has not been peer-reviewed by CIE.

(C) CIE 2019

All rights reserved. Unless otherwise specified, no part of this publication may be reproduced or utilized in any form or by any means, electronic or mechanical, including photocopying and microfilm, without permission in writing from CIE Central Bureau at the address below. Any mention of organizations or products does not imply endorsement by the CIE.

This paper is made available open access for individual use. However, in all other cases all rights are reserved unless explicit permission is sought from and given by the CIE.

CIE Central Bureau

Babenbergerstrasse 9

A-1010 Vienna

Austria

Tel.: +4317143187

e-mail: ciecb@cie.co.at

www.cie.co.at 


\title{
ANALYSIS AND DESIGN APPROACH FOR A NOCTURNAL IMAGE OF THE CULTURAL LANDSCAPE
}

\author{
Valetti, L. ${ }^{1}$, Pellegrino, A. ${ }^{2}$ \\ ${ }^{1}$ Politecnico di Torino, Department of Architecture and Design, Torino, ITALY \\ 2 Politecnico di Torino, Department of Energy "Galileo Ferraris", Torino, ITALY
}

lodovica.valetti@polito.it

DOI 10.25039/x46.2019.PP27

\begin{abstract}
The current debate on the cultural landscape proposes active enhancement practices and local planning tools that are also dedicated to the study of scenic-perceptive components and visual values. However, the current indications are limited to the definition of day images of sites and are not based on investigations of the corresponding nocturnal images of the widespread heritage. The study presented in this paper is aimed at underlining the importance of the analysis of nocturnal images and at defining design tips and guidelines for the definition of the nocturnal landscape image. The proposal of design guidelines will result from the assessment of the current nightscape. The aim of the paper is to present the methodological approach that has been conceived to address the analysis of the current nocturnal landscape image, carried out through both qualitative and quantitative analysis. In the paper results obtained from the application of the method to a case study are presented.
\end{abstract}

Keywords: Cultural landscape, nocturnal image, luminance images, measurement campaign.

\section{Introduction}

The topic of cultural heritage and protection and enhancement practices has witnessed a growing interest in contemporary culture. The concept of heritage has been transformed and stratified and a more complex articulation has been reached (Vecco, 2010). We have progressively moved away from the concept of cultural good, meaning a single object with a historical value, to cultural landscape (World Heritage Centre, 2003), which is considered as an inclusive system of cultural heritage and territorial context, generated by the joint efforts of humans and nature. The will to try to overcome the concept of individual cultural goods, in order to achieve a more articulated and extended vision of heritage, which considers both individual features and relationships, requires an interdisciplinary approach and new research dynamics. In the pursuit of these objectives, the landscape planning, management and control instruments are gradually being updated, integrating new strategies with traditional policies aimed at including such elements as perceptual components, landscape connection networks, visual values and enhancement of the scenic-perceptive aspects (Cassatella, 2011). However, the current indications are limited to the definition of day images of sites and are not based on investigations of the corresponding nocturnal images. Over the decades, lighting from a simple infrastructure has become one of the main components of an urban project; nevertheless, this innovative reflection is limited, in most cases, at the physical borders of the cities. The territory surrounding the cities and the variety of urban landscapes are absent from the nocturnal imagery (Narboni, 2004).

The study of sectoral legislation shows that, in most cases, quantitative requirements regarding such functional aspects as safety, the containment of energy consumption and limitation of light pollution are provided. However, the decisions concerning the qualitative and communicative aspects of light are delegated to the designer. In addition, the criteria adopted for the lighting project of widespread cultural heritage sites coincide with those dictated by the functional requirements or those that are associated with the architectural lighting interventions of single monuments and buildings. In other words, there are no indications on how to guarantee the enhancement of the nocturnal image of the cultural landscape as a whole, through criteria that allow the construction of a harmonious image, as a result of a targeted project using a coordinated language. 


\subsection{The state of affair}

In order to investigate the current state of lighting in landscape contexts, a preliminary critical analysis of the present situation was conducted. The aim was to obtain knowledge on the state of affairs in territories with strong landscape connotations, characterised by widespread settlements or villages and therefore of widespread heritage importance.

A preliminary study of the current condition was conducted. The analysis was limited to the Italian context, and in particular to territorial morphologies that guarantee visibility and visual relationships from multiple observation points, not only inside urban settlements but above all outside them, in correspondence to road networks and relevant places of use of the territory.

The analysis was conducted through a collection of nocturnal photos, thanks to which an overview of different and representative cases distributed throughout the national territory was obtained. The survey was developed for cognitive purposes and was therefore not intended to be exhaustive of the entire complexity of the Italian landscape, but to allow some critical reflection.

Figure 1 shows an example of the collected images, related to different contexts identified throughout the national territory.
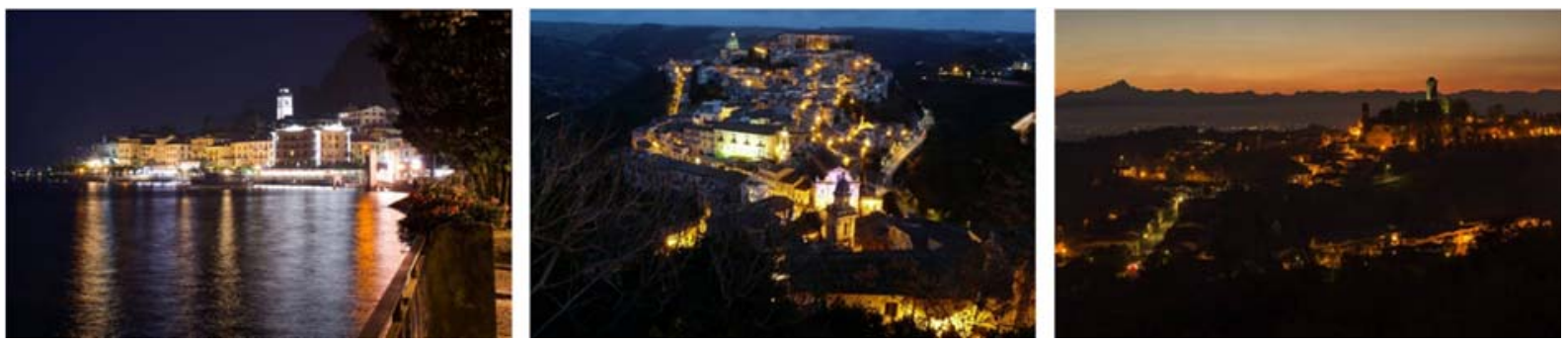

Figure 1 - Examples night images, related to different context throughout the Italian territory (Bellagio, Ragusa Ibla, Murazzano; Italy)

The critical analysis of the images made it possible to draw up some preliminary critical considerations. In most cases, the absence of a strategy that was able to connect the settlements and the landscape in a coordinate system was evident. The consequence was the lack of an overall perception of the settlements and of the context, where at night only some elements, considered to be the most significant, were highlighted. In most cases, this strategy involved discomfort in the general perception of the site and an excessive and annoying luminance contrast. Moreover, it was possible to observe in some cases the use of light sources characterised by different colour temperatures, that was not results of design choices.

As a general comment from the analysis, it emerged that, in most cases, there was a general lack of attention to the nocturnal design of the image of the cultural landscape. Obviously, it would be impossible to illuminate all the elements of the territory; however, innovative strategies could be directed towards creating lighting scenarios, based on the definition of a specific nocturnal image.

\section{Methods}

Based on the preliminary analysis of the current state of lighting, a research project on the nocturnal image of territorial contexts with variable morphological characteristics, that is, of small urban settlements and widespread architectural assets, was launched. The research project was aimed, on one hand, at raising the issue and promoting the debate on the topic, and, on the other hand, at defining design tips and guidelines for the definition of the nocturnal landscape image. The proposal of design guidelines will result from the assessment of the current nightscape, carried out through both qualitative and quantitative analysis.

Within this frame, the aim of this paper is to describe the research method that has been conceived to address the analysis of the nocturnal landscape image, to present the case study that was selected for the application of the research method and to provide some results and data elaborations referred to the application of the research methodology to the case study. 
The methodological approach conceived for this research project can be divided into three phases as described in Figure 2.

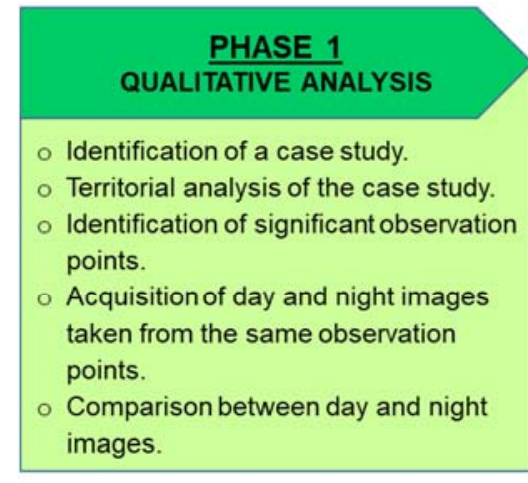

Qualitative and subjective judgement

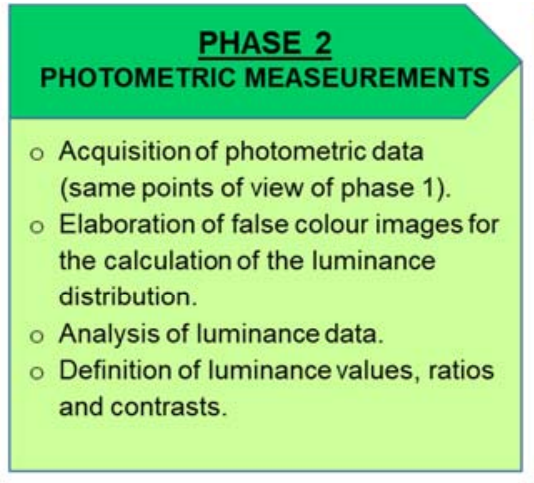

Quantitative description of the lightscape

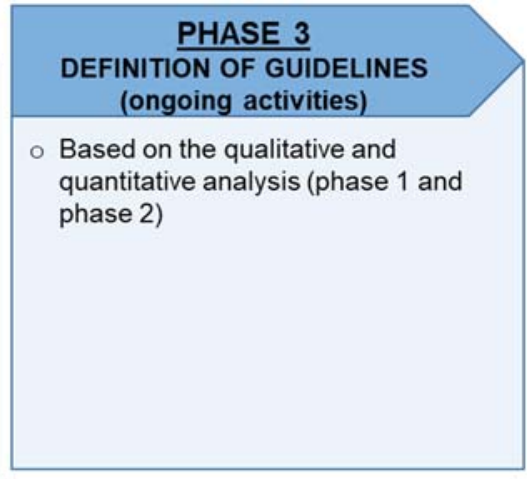

Definition of design guidelines

Figure 2 - Description of the methodological approach

The first phase of the proposed methodology was aimed at analysing the case study and collecting qualitative data. Once the case study was chosen, a multidisciplinary analysis of the territory was developed, using the main land planning and management plans. From this analysis data concerning the spatial organization, location of the main buildings, land uses, historical aspects, main access roads and scenic and tourist routes were collected. The analysis was conceived to define the main characters of the case study and to identify the most relevant points of observation from which to analyse and subsequently define the nocturnal image of the widespread heritage. For the identification of significant observation points, priority was given to points of view outside the settlement, located along the main roads and touristic routes in the territory. From the selected observation points, photographic investigations were carried out in order to investigate the image of some representative case studies of recurrent territorial situations. The survey was conducted by comparing day and night photographs taken from analogous observation points.

The second phase was an in situ measurement campaign, carried out in order to obtain quantitative data on the current lighting condition. The collection of photometric data is necessary to define the luminance ratios and contrasts, as indications of the current condition, which are useful to compare data on different sites and to develop critical considerations and the subsequent design proposals.

The analysis can be conducted by means of luminance measurements, because this is the most representative photometric measurement of the brightness perceived when an object or a set of illuminated objects are observed (Kruisselbrink et al., 2018).

In this study, an "LMK Mobile" TechnoTeam videophotometer (based on a Canon EOS digital camera) was used in the measurement campaign to evaluate the luminance distribution of the considered areas. The LMK Mobile videophotometer is design to convert images into luminance values. Different kinds of camera lens were used in order to take images of the entire settlement and detailed images of selected areas or relevant buildings. The associated TechnoTeam's software "LMK LabSoft" was used in order to acquire data from the camera, using the corresponding calibration file, and to elaborate them. Results were expressed as false colour images.

The third phase of the research project, which is not subject of this paper, will concern the further elaboration of qualitative and quantitative data, in order to propose guidelines to support the lighting design for these territorial contexts.

This paper reports some results obtained in the application of the first two phases of the proposed methodology to a case study. These parts of the method are fundamental in order to critically evaluate the current nocturnal lighting condition and to provide qualitative (visual 
survey) and quantitative (acquisition and elaboration of instrumental data) indications for the definition of design guidelines.

\section{Case study}

In defining the case study, attention was paid to the extra-municipal scale, considering systems and relationships between landscapes, settlements and architectures. In particular, the analysis was related to territorial morphologies that guarantee visibility and visual relationships from multiple observation points, not only inside the urban settlements but in particular outside them, in correspondence to road networks and relevant places in the territory.

The territory identified as case study is the UNESCO site "Vineyard Landscape of Piedmont: Langhe-Roero and Monferrato", in Italy. Some widespread settlements were chosen within this territory to which the methodological approach was applied.

The site is located in the Piedmont Region, that has recently promoted particular attention to the scenic aspects and to landscape connection networks in its local landscape management tools: the Regional Landscape Plan (Piedmont Region, 2009) and the Guidelines for the analysis, protection and enhancement of the landscape characteristics (Cassatella, 2014). These tools provide guidance to help understand and manage the relationships and links between the components of the landscape. These indications, which currently refer to the day images of the places and the management of the interventions, could benefit from the parallel definition of a methodology for the definition of the nocturnal images of the same sites.

Moreover, the Piedmont Region has recently updated a Regional Law (Piedmont Region, 2018) in order to reduce light pollution.
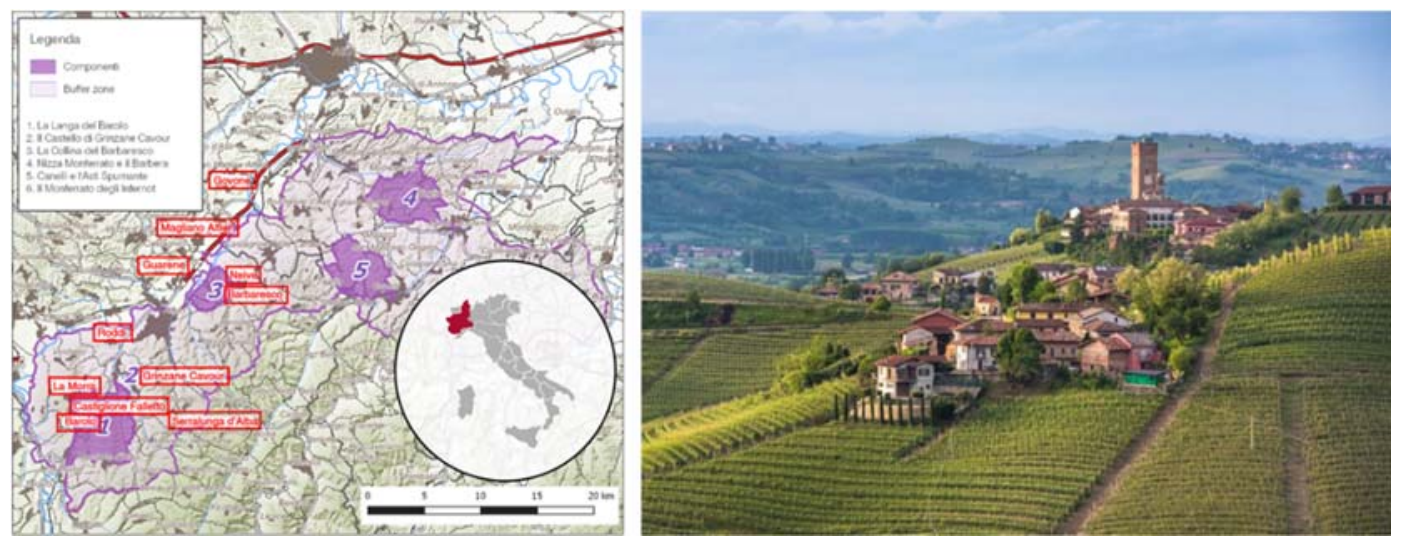

Figure 3 - Identification of the case study

The selected site is recognised as a cultural landscape and has an undisputed environmental and cultural value at an international level, which can be confirmed from the UNESCO recognition of 2014 (UNESCO, 2014). It is a serial site, composed of six components that are protected by a large buffer zone.

As it is possible to read in the description of the Serial Nomination (UNESCO, 2014), the property, which has a relatively homogenous tonality of landscape, covers a great diversity of features pertaining to its composition and its winegrowing and winemaking activities. The landscape is dotted with farms, winegrowers' huts (ciabot), isolated winegrowing farms, villages, which are often perched on high ground, larger towns on the edge of the vineyards, castles, Romanesque churches and ancient monastic buildings. The property contains highly diverse built components, which provide a large number of significant landmarks in the vineyard landscape and in the urban village settings.

The area was chosen as a case study because it presents interesting characteristics from both the point of view of the recurrent morphology of the settlements (Piedmont Region, 2015), which are mainly characterised by a circumscribed village in a prominent position, and because of the value of the surrounding landscape. 


\section{Results}

In this paper data elaborations and results concerning one of the municipalities of the case study are reported as an example of the application of the research methodology. The presented results are relative to two selected observations points of the municipality of Govone (CN, Italy).

\subsection{Qualitative analysis}

The first phase of the proposed methodology consists of a qualitative analysis. The case study was analysed through the study of its morphological, perceptive and functional aspects. From the knowledge of the area and the analysis of the main roads and touristic routes, some significant observation points, representative of the relationship between settlement, architectonic goods and landscape context, and located on the main communication and access roads, were selected. Figure 4 shows the territorial analysis conducted for the municipality of Govone and the location of the two observation points (P1 and P2) selected for the qualitative and quantitative analysis.

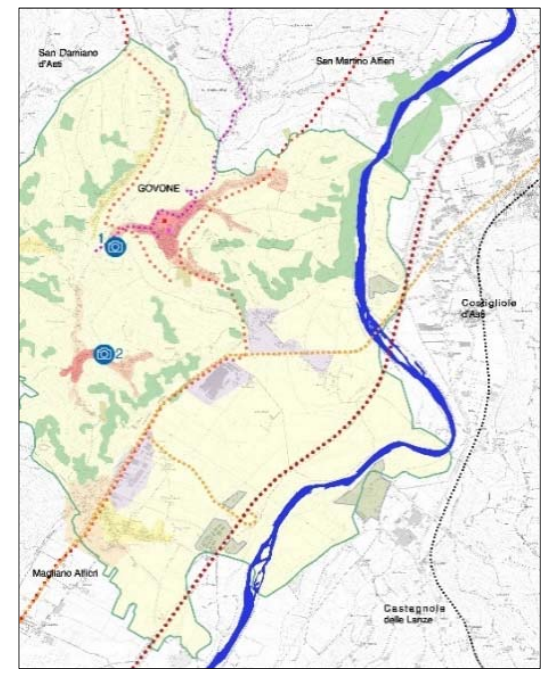

Figure 4 - Example of a table of the territorial analysis, Govone (CN, Italy)

The qualitative analysis involved the direct observation of the sites, through a comparison of photographs taken both during the day and at night, from the same observation points. The analysis confirmed the problems that had already emerged in the preliminary analysis carried out to assess the state of affairs at a national level. However, the comparison between the day and night images and the choice of the observation points made it possible to draw up more detailed considerations based on the direct knowledge of the case study. Diurnal and nocturnal pictures taken from both observation points are reported in Figure 5 and 6.
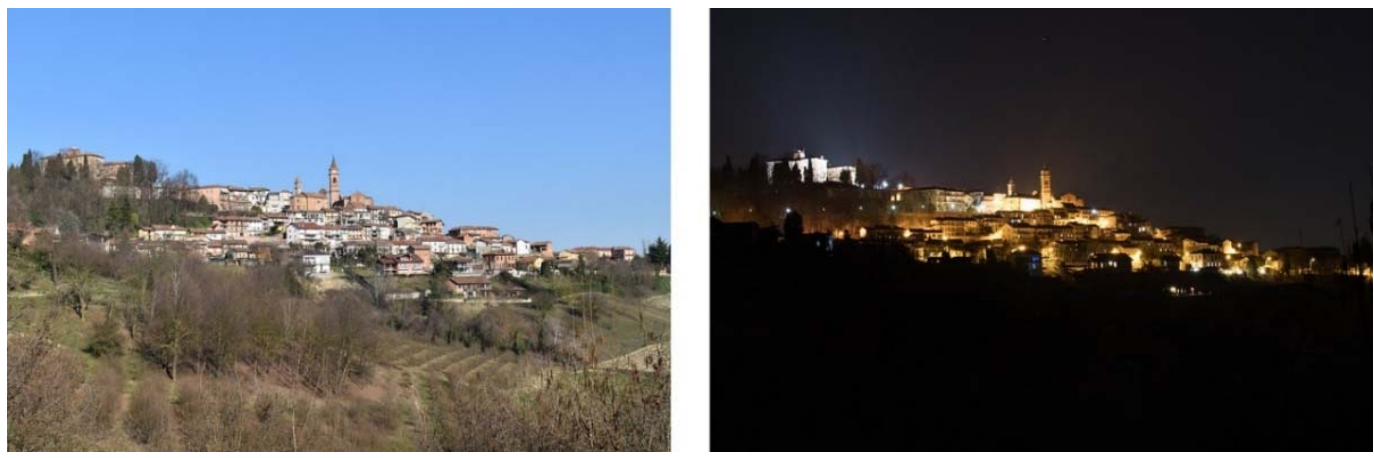

Figure 5 - Daytime and night-time images. Municipality of Govone, Italy. (P1) 

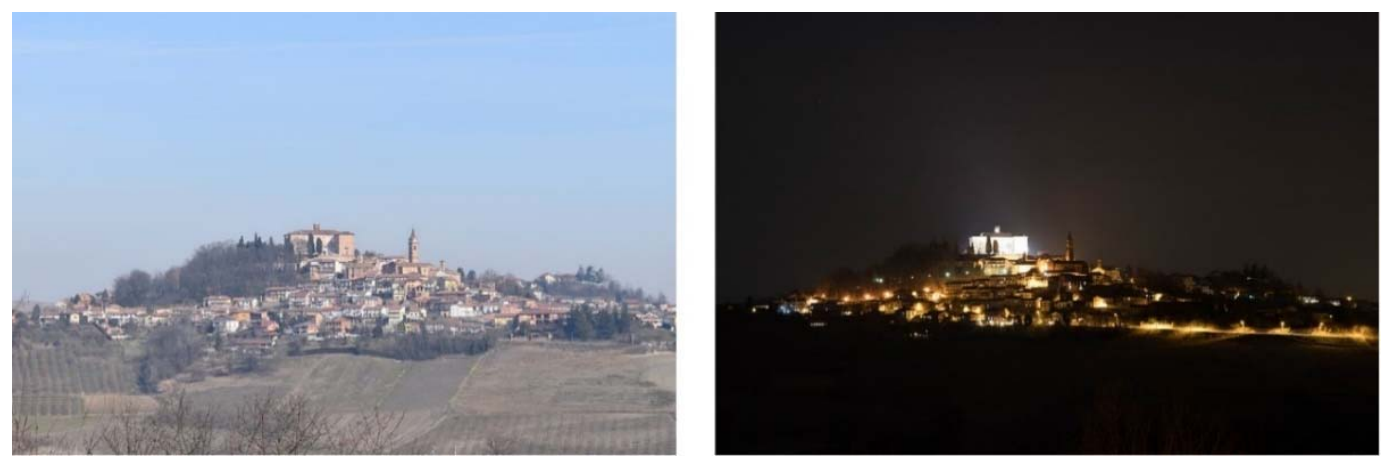

Figure 6 - Daytime and night-time images. Municipality of Govone, Italy. (P2)

From the comparison between pictures, it was possible to draw up some critical considerations. The daytime and night-time images of the landscape captured from the two observation points were critically compared. Moreover, a comparison between the night-time images taken from the two observation points was carried out in order to analyse the nocturnal perception of the sites. The comparison was based on some simple visibility criteria that were considered to be relevant in defining the image of the settlement (1 -visibility; 2 -standing out; 3 -complete visibility; 4 -lighting uniformity; 5 -relation with the settlement). Furthermore, the analysis was applied to the settlement as a whole and to the parts of the settlement that, in the territorial analysis, were identified as prominent from an historical, cultural or architectonical point of view (castle and parish area). Table 1 summarizes the results of the critical comparison between images for the two observation points.

Table 1 - Qualitative analysis. Comparison between pictures from the two observation points

\begin{tabular}{|c|c|c|c|c|c|}
\hline \multirow{2}{*}{ Elements } & \multirow{2}{*}{ Evaluation criteria } & \multicolumn{2}{|c|}{ Observation point 1 (P1) } & \multicolumn{2}{|c|}{ Observation point 2 (P2) } \\
\hline & & Day & Night & Day & Night \\
\hline \multirow{5}{*}{ Castle } & Visibility & $\checkmark$ & $\checkmark$ & $\checkmark$ & $\checkmark$ \\
\hline & Standing out & $\checkmark$ & $\checkmark$ & $\checkmark$ & $\checkmark$ \\
\hline & Complete visibility & $\sim$ & $\sim$ & $\checkmark$ & $\checkmark$ \\
\hline & Lighting uniformity & & $\begin{array}{l}\text { Very high } \\
\text { uniformity }\end{array}$ & & $\begin{array}{l}\text { Very high } \\
\text { uniformity }\end{array}$ \\
\hline & $\begin{array}{l}\text { Relation with the } \\
\text { settlement }\end{array}$ & & $\begin{array}{c}\text { Too high luminance } \\
\text { contrast } \\
\text { Too high chromatic } \\
\text { contrast }\end{array}$ & & $\begin{array}{c}\text { Too high luminance } \\
\text { contrast } \\
\text { Too high chromatic } \\
\text { contrast }\end{array}$ \\
\hline \multirow{5}{*}{$\begin{array}{l}\text { Parish } \\
\text { area }\end{array}$} & Visibility & $\checkmark$ & $\checkmark$ & $\checkmark$ & $\sim$ \\
\hline & Standing out & $\checkmark$ & $\checkmark$ & $\checkmark$ & 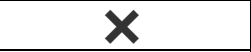 \\
\hline & Complete visibility & $\checkmark$ & $\checkmark$ & $\checkmark$ & $\sim$ \\
\hline & Lighting uniformity & & Low uniformity & & Low uniformity \\
\hline & $\begin{array}{l}\text { Relation with the } \\
\text { settlement }\end{array}$ & & $\begin{array}{c}\text { High luminance } \\
\text { contrast }\end{array}$ & & $\begin{array}{c}\text { High luminance } \\
\text { contrast }\end{array}$ \\
\hline \multirow{3}{*}{ Settlement } & Visibility & $\checkmark$ & $\checkmark$ & $\checkmark$ & $\sim$ \\
\hline & Standing out & $\checkmark$ & $\sim$ & $\checkmark$ & $x$ \\
\hline & Complete visibility & $\checkmark$ & $\checkmark$ & $\checkmark$ & $\sim$ \\
\hline
\end{tabular}

From the comparison between day and night pictures, it emerged that the castle was visible during the day from both observation points. However from the first observation point the visibility was not complete because of the presence of vegetations. Also, at night time the castle was clearly visible from both points of view and uniformly enlightened on all facades. However, the high illumination of the whole building and the cool white light, opposed to an almost inexistent illumination of the surrounding, led to excessive luminance and chromatic contrasts that rendered a non-coordinated perception of the system as a whole.

The parish was completely visible during the day from both observation points and highly recognizable due to its architectural characters. In night time the parish buildings were entirely 
visible and stood out from the settlement when observed from the first point of view; from the second observation point the parish was not clearly distinguishable, with the exception of some facades of the churches which resulted to be over lit. From both points of view the lighting of the facades were not uniform and the relation between the parish and the settlement was critical due to the high luminance contrasts. Moreover, it was possible to observe that some elements, the bell tower for example, are only lighted on one side, thus making this element clearly visible from the fist point of view, but barely visible from the second.

The settlement was the larger part of the framed area and included the urban constructions. This built-up area was clearly recognizable during the day from both observation points. During the night, although the settlement was entirely recognizable from both points of view, the level of visibility was higher from the first observation point than from the second. Furthermore, from the night images it emerged that the general lighting of the facades was a consequence of the street lighting.

Finally, it was possible to observe that during the day time the surrounding natural context was clearly visible and that it was possible to recognise the different types of cultivation, related to the winegrowing and winemaking activities. The comparison between the pictures showed that during the night-time the context was not visible and the naturalistic value of the surrounding landscape was missing.

\subsection{Quantitative analysis}

The second phase of the analysis was aimed to quantitative analyse the nocturnal lighting conditions. The pictures taken with the camera were converted into luminance distributions and represented through false-colour images. The luminance images were further elaborated in order to extrapolate luminance values, define luminance hierarchies, evaluate luminance distributions and luminance contrasts within the perceived scene. The objective of this second phase of analysis was to identify luminance values and ratios which characterise the present nocturnal lighting condition. Figure 7 and Figure 8 show the false colour images related to the two observation points.

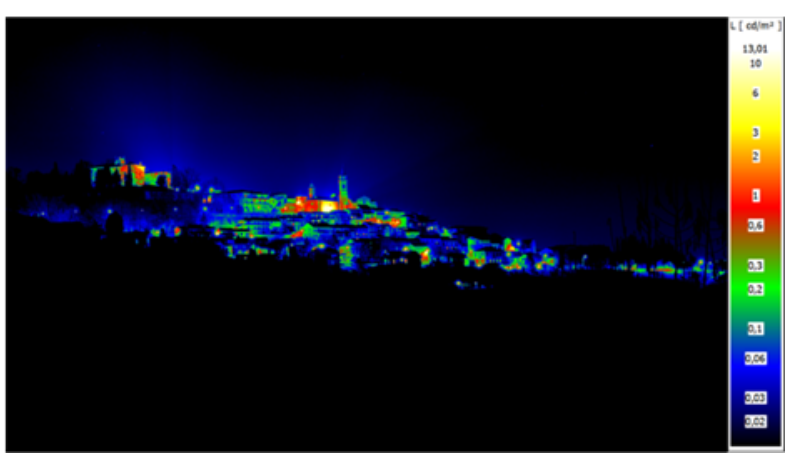

Figure 7 - Luminance distribution expressed as a false colour image. P1

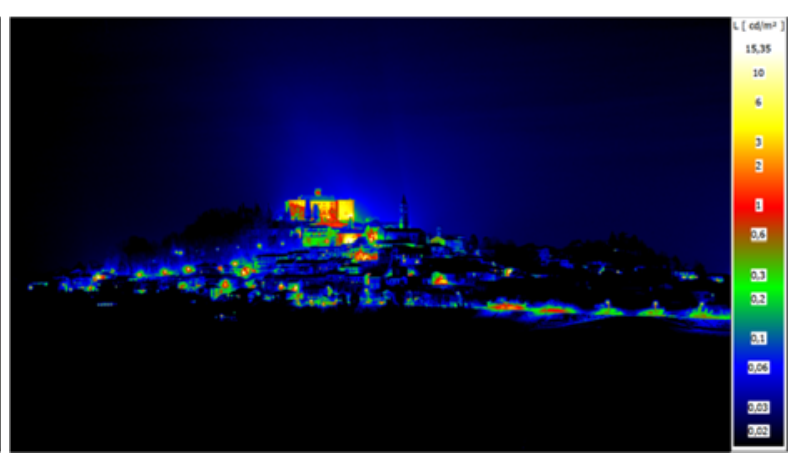

Figure 8 - Luminance distribution expressed as a false colour image. P2

Based on the territorial analysis performed in the previous phase, the settlement was ideally divided into four regions. Region 1 corresponded to the upper part of the settlement and was characterized by the presence of the prominent building, which was the castle. Region 2 was the more historical part of the settlement and included the parish area. Region 3 corresponded to an historical part of the residential settlement. Region 4 was the lower part of the settlement and included a more recent expansion of the residential area.

Figure 9 and Figure 10 show the identification of the regions for both points of view. 


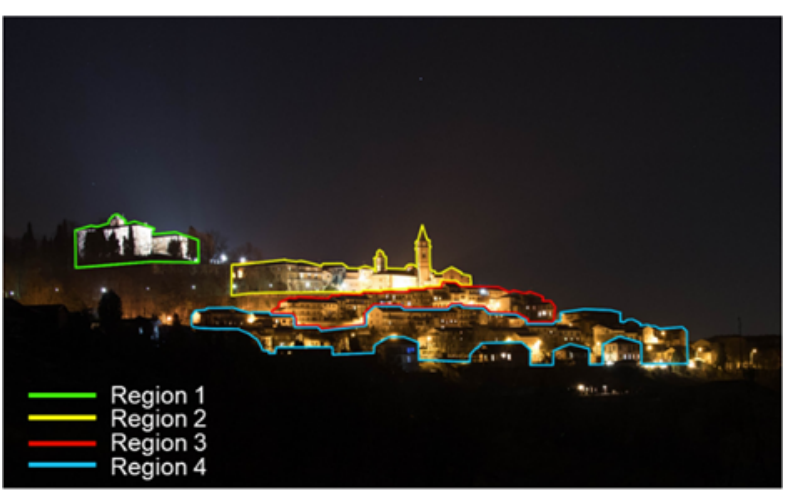

Figure 9 - Regions from P1

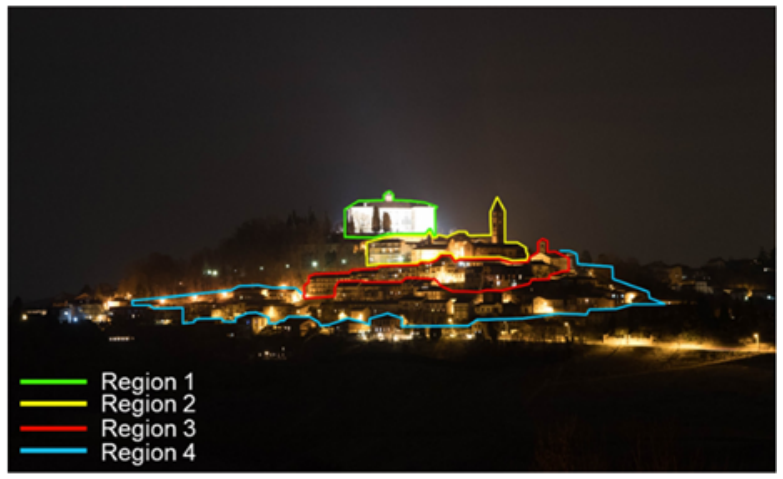

Figure 10 - Regions from P2

For each region the percentage area, luminance values (maximum, mean and minimum) and dispersion values were calculated. Moreover, further elaborations were performed in order to analyse the luminance distribution of the nocturnal image of the settlement.

Three luminance classes were identified by mean of threshold values:

- Bright areas: luminance values above $2 \mathrm{~cd} / \mathrm{m}^{2}$

- Intermediate areas: luminance values between $2 \mathrm{~cd} / \mathrm{m}^{2}$ and $0,1 \mathrm{~cd} / \mathrm{m}^{2}$

- Dark areas: luminance values less than $0,1 \mathrm{~cd} / \mathrm{m}^{2}$

Figure 11-12 show the comparison, for each point of observation and for each region, of the mean luminance values and of the percentage area corresponding to each luminance class.

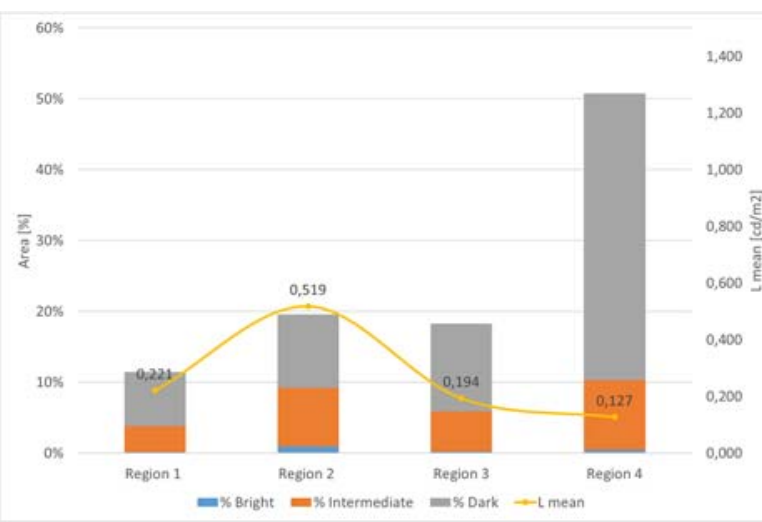

Figure 11 - Comparison between the four regions. P1

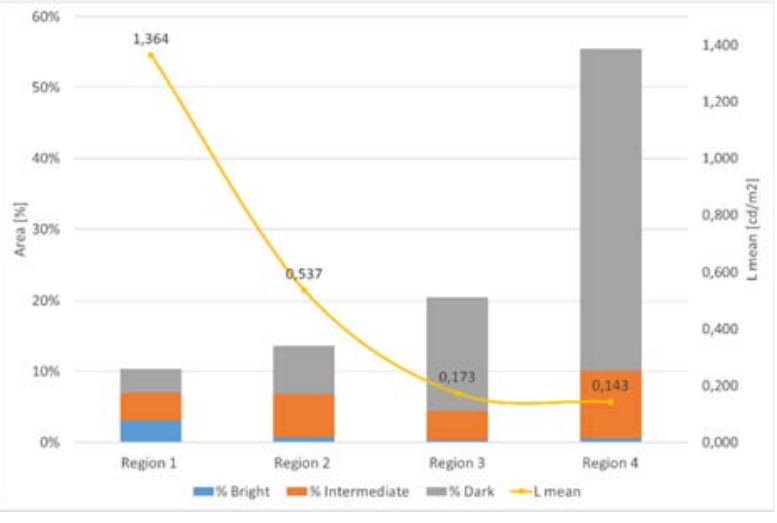

Figure 12 - Comparison between the four regions. P2

The data show that for both observation points, Region 1 (that included the castle) and Region 2 (that included the parish) presented the highest values of mean luminance. The Region 2 was characterized by similar mean luminance values for both points of view (respectively 0.519 $\mathrm{cd} / \mathrm{m}^{2}$ and $0.537 \mathrm{~cd} / \mathrm{m}^{2}$, with relative percentage difference of $3.56 \%$ ). In Region 1 , also due to the presence of vegetation in the first observation point, the values of the mean luminance were significantly different for the two point of view $\left(0.221 \mathrm{~cd} / \mathrm{m}^{2}\right.$ for point 1 and $1.364 \mathrm{~cd} / \mathrm{m}^{2}$ for point 2 ). Regions 3 and 4 were characterized by progressively lower values of mean luminance, below $0.2 \mathrm{~cd} / \mathrm{m}^{2}$ for both observation points.

The regions that included the more prominent and historical architectures of the settlement (Region 1 and Region 2) were those with the larger area under Bright luminance class. In particular from the second point of view a significant part of Region 1 was included in Bright and Intermediate classes (respectively $29 \%$ and $38 \%$ of the total area of the Region). In Region 2 a lower part of the area was under Bright class $(5 \%$ of the total area of the Region for both observation points) and a significant area was under Intermediate class (respectively $42 \%$ for the first observation point and $44 \%$ for the second). Regions 3 and 4 , which included the 
residential areas of the settlement, were characterized by a progressive increasing of the area under Dark class from both points of view (for Region 3 respectively $68 \%$ and $79 \%$ of the total area of the Region; for Region 4 respectively $80 \%$ and $82 \%$ ).

In order to analyse the luminance condition within each region, further elaborations were carried out. Using LMK Labsoft, for each region a polyline passing through the surfaces which mainly contribute in defining the image of the settlement was draw up. Figure 13 shows the position of each polyline in the four regions for the two observation points and the luminance profile along each polyline represented by sectional view. Moreover, the minimum, mean and maximum luminance values and the dispersion values of the polylines were reported.

Luminance values show that Region 1 had similar maximum luminance values from both points of view $\left(4.446 \mathrm{~cd} / \mathrm{m}^{2}\right.$ and $4.471 \mathrm{~cd} / \mathrm{m}^{2}$ respectively). However, the mean luminance values were significantly different from the two observation points (respectively $1.003 \mathrm{~cd} / \mathrm{m}^{2}$ and 2.597 $\mathrm{cd} / \mathrm{m}^{2}$ ). The comparison between the luminance profiles of Region 1 show that for the first observation point most of the luminance values of the polyline were significantly lower than the maximum value, while from the second observation point the luminance profile was more even and a significant part of the luminance values along the polyline were close to the maximum value. 


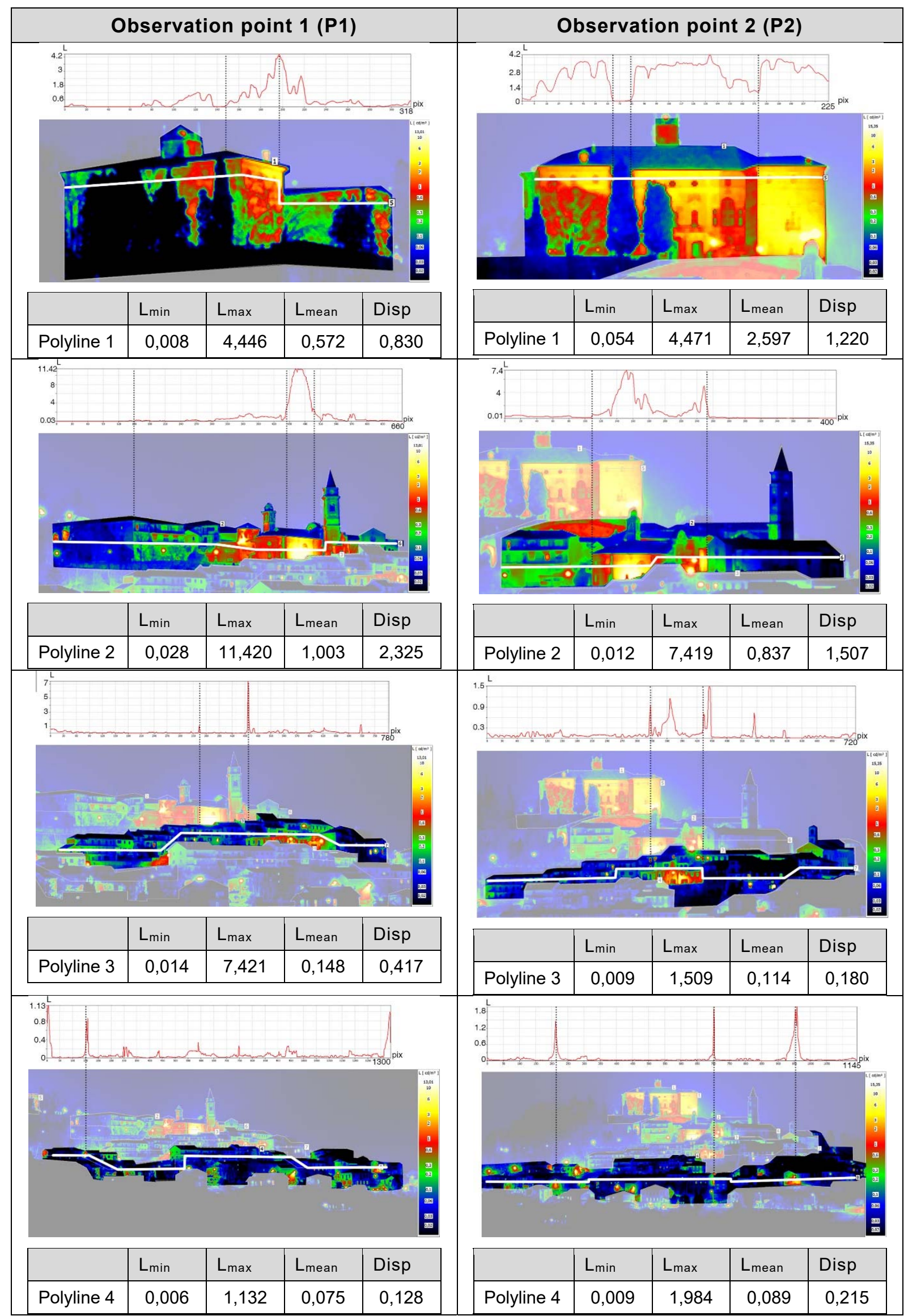

Figure 13 - Luminance profiles along the polylines represented by sectional view; false colour images of the regions; luminance values and dispersion values of the polylines 
Region 2 was characterized by the highest mean luminance values from both points of view (respectively $11.420 \mathrm{~cd} / \mathrm{m}^{2}$ and $7.419 \mathrm{~cd} / \mathrm{m}^{2}$ ). The dispersion values in the Region was higher than in other regions (respectively 1.507 for the first observation point and 2.325 for the second observation point). These data confirm that in Region 2 lighting distribution was not uniform and some elements (some façades of the parish) were over lit while other under lit. The unevenness of the illumination concerned both the parish buildings with respect to the rest of the Region and the churches within the parish area. In this last case, the calculated luminance contrast values were respectively 9.169 and 18.334 for the two observation points.

The luminance distribution over the polyline shows that Region 3 had lower mean luminance values (respectively $0.148 \mathrm{~cd} / \mathrm{m}^{2}$ from P1 and $0.114 \mathrm{~cd} / \mathrm{m}^{2}$ from P2). Also the dispersion values were lower than for other regions, even though a peak in the graph of P1 can be observed, as a result of the intersection of the polyline with some framed luminaries.

A progressive decreases of mean luminance values from both points of view (respectively 0.075 $\mathrm{cd} / \mathrm{m}^{2}$ and $0.089 \mathrm{~cd} / \mathrm{m}^{2}$ ) were recorded in Region 4. The luminance profile and the low dispersion values also confirmed the lower level of illumination of this Region. As in Region 3 , the peaks in the luminance profile were a consequence of the intersection of the polyline with luminaries or with surfaces close to luminaires.

\section{Conclusions}

The paper presents a research method conceived to address the analysis of the nocturnal lightscape image of territorial contexts with variable morphological characteristics, that is, of small urban settlements and widespread architectural assets. The methodological approach for the analysis of the current condition was articulated in a qualitative analysis and a quantitative analysis. Results relative to a first application of the research method to a case study were presented. From the analysis of the data some initial considerations and indications on the current nocturnal landscape image emerged. The study is still in progress and future work will be focus on extending the research methodology to a significant number of samples in order to validate the analysis methodology. The further elaboration of the data can be the premises for design guidelines, aimed at the night-time enhancement of the sites that enjoy privileged visibility and inter-relationships between the settlements, the landscape context, and the viability system and tourist circuits.

\section{References}

CASSATELLA C. Assessing Visual and Social Perceptions of Landscape. in: CASSATELLA C., PEANO A. 2011. Landscape Indicators. Dordrecht: Springer.

CASSATELLA C. 2014. Guidelines for the analysis, protection and enhancement of the landscape characteristic. Research report, Italian Ministry for Cultural Heritage and Activities and Tourism MiBACT, Piedmont Region, Politecnico di Torino, DIST.

KRUISSELBRINK T., DANGOL R., ROSEMANN A. 2018. Photometric measurements of lighting quality: An overview. Building and Environment, 138 42-52.

NARBONI R. 2004. Le lumière et le paysage. Paris, Le Moniteur. English version: NARBONI R. 2004. Lighting the landscape. Basle: Birkhaüser publications.

PIEDMONT REGION 2009. Regional Landscape Plan. Decree number 53-11975, 2009.

PIEDMONT REGION 2015. Regional Landscape Plan, UNESCO site Vineyard Landscape of Piedmont: Langhe-Roero and Monferrato. Guidelines for the adjustment of the Development Plans and Building Codes to the indications for the protection of the UNESCO site. Decree number n.26-2131, 2015.

PIEDMONT REGION 2018. Piedmont Regional Law February 9, 2018, n. 3. Amendment to the Regional Law March 24, 2000, n. 31.

UNESCO World Heritage Centre 2003. Cultural landscapes: the challenges of conservation. Paris: UNESCO. 
Valetti, L., Pellegrino, A. ANALYSIS AND DESIGN APPROACH FOR A NOCTURNAL IMAGE OF THE ...

UNESCO 2014. Vineyard Landscape of Langhe-Roero and Monferrato (Italy). Doha, Quatar: UNESCO. www.whc.unesco.org/en/list/1390/documents

VECCO, M. 2010. A definition of cultural heritage: From the tangible to the intangible. Journal of Cultural Heritage, 11 321-324. 